\title{
Weight Reduction Improves Adipokines Profile and Glucose Control of Patients with Nonalcoholic Fatty Liver Disease
}

\author{
Shehab M Abd El-Kader ${ }^{1 *}$ Fadwa M Al-Shreef ${ }^{2}$ and Osama H Al-Jiffri ${ }^{2}$ \\ ${ }^{1}$ Department of Physical Therapy, King Abdulaziz University, Saudi Arabia \\ ${ }^{2}$ Department of Medical Laboratory Technology, King Abdulaziz University, Saudi Arabia
}

Submission: December 20, 2016; Published: February 17, 2017

"Corresponding author: Shehab Mahmoud Abd El-Kader, Faculty of Applied Medical Sciences, Department of Physical Therapy, King Abdulaziz University, P.0. Box 80324, Jeddah, 21589, Saudi Arabia, Email: profshehab@live.com

\begin{abstract}
Background: Non-alcoholic fatty liver disease (NAFLD) is a common health problem that usually associated with insulin resistance and obesity. The prevalence of NAFLD is about $15-20 \%$ of the general Asian population and affecting up to $30 \%$ of the population worldwide. At present, treatment options are limited and pharmacological management of NAFLD has had disappointing results. Lifestyle interventions (diet and exercise) are the standard treatment of NAFLD.
\end{abstract}

Objective: As the available previous studies involving the effects of weight loss on adipokines profile and glucose control of nonalcoholic fatty liver disease patients is limited in number; this study aims to measure response of adiopocytokines and glucose control response to weight reduction in patients with nonalcoholic fatty liver disease.

Methods: One hundred male patients with NAFLD were included into this study and divided into two equal groups. Group (A) received aerobic exercise training in addition to diet regimen. Group (B) received no treatment intervention.

Results: There was a $27.48 \%, 21.59 \%, 30.49 \%, 33.72 \%$ \& $10.67 \%$ reduction in mean values of leptin, resistin, insulin, HOMA-IR \& BMI respectively in addition to $35.69 \%$ \& $29.27 \%$ increase in the mean values of adiponectin \& QUICKI respectively in group (A) at the end of the study. The mean values of leptin, resistin, insulin, HOMA-IR \& BMI were significantly decreased in addition to significant increase in the mean values of adiponectin \& QUICKI of group (A) received aerobic exercise training in addition to diet regimen. While the results of group (B) received no treatment intervention were not significant. In addition, there were significant differences between mean levels of the investigated parameters of group $(\mathrm{A})$ and group $(\mathrm{B})$ after treatment $(\mathrm{P}<0.05)$.

Conclusion: Based on our findings, a $10 \%$ reduction in BMI is effective to improve glucose control and adipokines dysregulation in patients with non-alcoholic fatty liver.

Keywords: Non-alcoholic fatty liver; Adipokines; Insulin resistance; Weight reduction

\section{Introduction}

Non-alcoholic fatty liver disease (NAFLD) is the most common liver disease worldwide [1]. It is comprised of a spectrum of disorders characterized by liver steatosis with $>5 \%$ of hepatocytes infiltrated with fat in individuals with no history of alcohol abuse $(<30 \mathrm{~g} / \mathrm{d}$ in men and $<20 \mathrm{~g} / \mathrm{d}$ in women) and no competing etiologies for hepatic steatosis [2,3]. The presentation of the disease ranges from what can be considered as "silent liver disease", or fatty steatosis, to non-alcoholic steatohepatitis (NASH) [4]. Approximately $10 \%-25 \%$ of patients with silent liver disease develop NASH, and 5\%-8\% of those will develop liver cirrhosis within 5 years [2,5]. Furthermore, $12.8 \%$ of patients with liver cirrhosis will develop hepatocellular carcinoma (HCC) within 3 years [6].

Nonalcoholic fatty liver disease (NAFLD) is regarded as the hepatic component of metabolic or insulin resistance (IR) syndrome, increasing recently in parallel with the epidemics of obesity and type 2 diabetes mellitus (T2DM) [7,8]. NAFLD is now a global public health problem, with a prevalence of $10-46 \%$ in the general United States (US) population and of $6-35 \%$ in the rest of the world [9]. It is the most common cause of chronic 
liver disease in US adults. NAFLD ranges from nonalcoholic simple steatosis (SS) to nonalcoholic steatohepatitis (NASH) characterized by steatosis, inflammation and/or fibrosis [9]. However, IR and adipokines contribute to the pathogenesis of SS and the progression to NASH and NASH related cirrhosis [10]. NAFLD is also associated with an increased risk for developing cardiovascular disease, insulin resistance (IR), chronic kidney disease, post-operative complications after major liver surgery and colorectal cancer [11-13].

Obesity, especially visceral obesity, is frequently associated with NAFLD and their coexistence in the same individual increases the likelihood of having more advanced forms of liver disease [14]. NAFLD occurs in $60 \%-95 \%$ of people with obesity [15]. However, in cases of NAFLD associated with obesity, serum levels of leptin are increased [16]. Unlike other adipokines, serum levels of adiponectin are decreased in obesity and its associated medical complications [17]. Compared with healthy controls, adiponectin levels are lower by more than $50 \%$ in NASH patients [18]. Adiponectin expression is decreased by $20 \%-40 \%$ during the development of NAFLD, from simple steatosis to NASH [19]. In addition, Resistin is a hormone secreted from adipocytes that has a positive relationship with body composition characteristics and insulin resistance [20]. Increased insulin resistance follows the increase of resistin. However, its exact mechanisms are not known yet [21].

Visceral adipose tissue (VAT) is also a source of a number of secreted adipocyte-derived cytokines called adipokines [22]. The most well described adipokines are adiponectin, an insulin sensitizer, and leptin, a hormone mainly secreted by adipocytes [23], which play functional roles in NAFLD pathogenesis. Obesity is considered a state of central and peripheral leptin resistance, and obese individuals, as well as individuals with NAFLD and NASH, have higher circulating levels of leptin [24].

Recent studies use diet, physical activity and behavior modification to help promote weight loss in NAFLD patients [25]. Several studies have shown that weight loss is successful in improving liver enzymes, insulin sensitivity, reducing inflammation and liver histology [26-28]. A randomized controlled trial conducted by Promrat et al. [29] used a combination of diet, physical activity and behavior modification to trigger $7 \%-10 \%$ weight loss in obese NASH patients. Those who achieved a minimum of $7 \%$ weight loss had improvements in their liver histology.

The purpose of this study was to investigate the impact of weight reduction on glucose control and adipokines in type- 2 diabetic patients with NAFLD.

\section{Material and Methods}

\section{Subjects}

One hundred male patients with NAFLD with body mass index (BMI) ranged from 30 to $35 \mathrm{Kg} / \mathrm{m} 2$, their age ranged from
35 to 55 years. Participants were included in this randomized controlled study and divided into two equal groups; group (A) received physical training combined with dietary measures. The second group (B) received no intervention and considered as a control group. Participants were identified from a large number of patients attending the Liver Clinic in King Abdulaziz University Teaching Hospital, with a histological diagnosis of NAFLD. The diagnosis of NAFLD was based on the following criteria:

i. Elevated aminotransferases alanine and/or aminotransferase (AST and/or ALT)

ii. Liver biopsy showing steatosis in at least $10 \%$ of hepatocytes; and

iii. Appropriate exclusion of liver disease of other aetiology including alcohol- or drug-induced liver disease, autoimmune or viral hepatitis, cholestatic or metabolic/ genetic liver disease. These other liver diseases were excluded using specific clinical, biochemical, serologic tests radiographic and/or histological criteria.

Exclusion criteria included smoking; hypertension, personal history of cardiovascular diseases, thyroid disease and orthopedic problems inhibiting treadmill training. This study was approved by the Scientific Research Ethical Committee, Faculty of Applied Sciences, King Abdulaziz University. Informed consent was obtained from all participants. All participants were free to withdraw from the study at any time. If any adverse effects had occurred, the experiment would have been stopped, with this being announced to the Human Subjects Review Board.

\section{Evaluated parameters}

Measurement of glucose control and adiopkines markers serum level: After a 10 hours overnight fast, venous blood samples were drawn to determine levels of leptin, adiponectin and resistin. Serum level of leptin was measured with DRG leptin ELISA Catalog number EIA-2395, supplied by DRG instruments $\mathrm{GmbH}$, Germany and serum level of adiponectin was determined using AviBion human adiponectin (Acrp 30) ELISA kit ref. no. ADIPO 25 (Orgenium Laboratories, Finland), while serum level of resistin was measured by ELISA using commercially available kits (resistin: Rapidbio, West Hills, CA, USA; CK-18: PEVIVA, Alexis, Grunwald, Germany) according to the manufacturer's instructions. Human insulin was measured with an insulin kit (Roche Diagnostics, Indianapolis, IN, USA) using a cobas immunoassay analyzer (Roche Diagnostics). Insulin resistance was assessed by homeostasis model assessment (HOMA-IR). HOMA-IR = [fasting blood glucose $(\mathrm{mmol} / \mathrm{l}) \ldots$ fasting insulin $(\mathrm{mIU} / \mathrm{ml})] / 22.5$ [30]. However, insulin sensitivity was assessed by The quantitative insulin-sensitivity check index (QUICKI) using the formula: QUICKI=1/ [log(insulin) + $\log$ (glucose)] [31] All serum samples were analyzed in duplicates.

Body mass index (BMI): Body weight of participants in both groups was measured (HC4211, South Korea) while wearing 
hospital gowns and undergarments. Where the height was measured using digital stadiometer (JENIX DS 102, Dongsang). Body Mass Index (BMI) was computed as BMI= Body weight/ Height2. The international standard definition of obesity was used. Patients were classified as underweight (BMI $\leq 18.5$ ), normal $(18.5 \leq \mathrm{BMI} \leq 25)$, overweight $(25 \leq \mathrm{BMI} \leq 30)$, or obese $(\mathrm{BMI} \geq 30$ ).

\section{Procedures}

The physical training program: The aerobic treadmillbased training program (PRECOR 9.1/ 9.2, China) was set to 65\%-75\% of the maximum heart rate (HRmax) according to a modified Bruce protocol. This rate was defined as the training heart rate (THR). After an initial, 5-minute warm-up phase performed on the treadmill at a low load, each endurance training session lasted 30 minutes and ended with 5-minute recovery and relaxation phase. All patients performed three weekly sessions (i.e. 36 sessions per patient over a 3-month period).

The prescribed low calorie diet: The interview-based food survey was performed for all patients by dieticians to specify previous food habits and possible anomalies in dietary behavior. The prescribed low calorie diet was balanced, with $15 \%$ as protein, 30 to $35 \%$ as fat and 50 to $55 \%$ as carbohydrate, on average, in order to provide about 1200 Kilocalories daily for two months for whole participants in this study.

\section{Statistical Analysis}

The mean values of leptin, adiponectin, resistin, HOMA-IR, QUICKI and BMI obtained before and after three months in both groups were compared using paired " $t$ " test. Independent " $t$ " test was used for the comparison between the two groups $(\mathrm{P}<0.05)$.

\section{Results}

One hundred patients with NAFLD were enrolled including 53 women and 47 men, their age ranged from 35 to 55 years. Participants were included in this randomized controlled study and divided into two equal groups; group (A) received physical training combined with dietary measures, while group (B) received no intervention and considered as a control group. The two groups were considered homogeneous regarding the demographic and clinical variables (Table 1 ).
Table 1: Mean value of demographic data for participants in both groups.

\begin{tabular}{|c|c|c|}
\hline & \multicolumn{2}{|c|}{ Mean +SD } \\
\hline & Group (A) & Group (B) \\
\hline Age (year) & $48.18 \pm 7.53$ & $46.95 \pm 6.82$ \\
\hline Gender (F/M) & $27 / 23$ & $26 / 24$ \\
\hline Weight (kg) & $91.19 \pm 5.42$ & $90.22 \pm 7.16$ \\
\hline Height $(\mathrm{cm})$ & $174.82 \pm 8.36$ & $176.12 \pm 9.24$ \\
\hline waist hip ratio & $0.925 \pm 0.041$ & $0.913 \pm 0.052$ \\
\hline BMI (kg/m2) & $33.17 \pm 2.87$ & $32.46 \pm 3.15$ \\
\hline $\begin{array}{l}\text { Fasting glucose(mg/ } \\
\text { dl) }\end{array}$ & $148.26 \pm 15.21$ & $146.18 \pm 16.72$ \\
\hline Insulin (mU/l) & $16.17 \pm 3.95$ & $15.91 \pm 3.51$ \\
\hline AST (IU) & $65.44 \pm 9.47$ & $63.82 \pm 7.19$ \\
\hline ALT (IU) & $53.63 \pm 8.22$ & $52.31 \pm 9.18$ \\
\hline AST/ALT & $1.16 \pm 0.73$ & $1.13 \pm 0.65$ \\
\hline $\begin{array}{l}\text { Total cholesterol } \\
\text { (mg/dl) }\end{array}$ & $197.24 \pm 22.81$ & $193.78 \pm 25.22$ \\
\hline HDL-C (mg/dl) & $32.61 \pm 5.48$ & $35.10 \pm 6.37$ \\
\hline LDL-C (mg/dl) & $124.50 \pm 14.61$ & $122.72 \pm 13.23$ \\
\hline $\begin{array}{l}\text { Triglycerides (mg/ } \\
\text { dl) }\end{array}$ & $162.11 \pm 18.75$ & $158.97 \pm 15.42$ \\
\hline
\end{tabular}

BMI: Body mass index; AST: Aspartate aminotransferase; ALT: alanine aminotransferase; AST/ALT: Aspartate aminotransferase /alanine aminotransferase ratio; HDL-c: High density lipoprotein cholesterol; LDL-c: Low density lipoprotein cholesterol.

There was a $27.48 \%, 21.59 \%, 30.49 \%, 33.72 \%$ \& $10.67 \%$ reduction in mean values of leptin, resistin, insulin, HOMA-IR \& BMI respectively in addition to $35.69 \% \& 29.27 \%$ increase in the mean values of adiponectin \& QUICKI respectively in group (A) at the end of the study. The mean values of leptin, resistin, insulin, HOMA-IR \& BMI were significantly decreased in addition to significant increase in the mean values of adiponectin \& QUICKI of group (A) received aerobic exercise training in addition to diet regimen. While the results of group (B) received no treatment intervention were not significant. Also, there were significant differences between mean levels of the investigated parameters in group (A) and group (B) after treatment (Table 2-4) $(\mathrm{P}<0.05)$.

Table 2: Mean value and significance of leptin, adiponectin, resistin, insulin, QUICKI, HOMA-IR and BMI of group (A) before and after treatment.

\begin{tabular}{|c|c|c|c|c|}
\hline & \multicolumn{2}{|c|}{ Mean +SD } & \multirow{2}{*}{ T-value } & \multirow{2}{*}{ Significance } \\
\cline { 2 - 5 } & Before & After & 6.83 & $\mathrm{P}<0.05$ \\
\hline BMI $\left(\mathrm{kg} / \mathrm{m}^{2}\right)$ & $33.17 \pm 2.85$ & $29.63 \pm 2.45^{*}$ & 6.21 & $\mathrm{P}<0.05$ \\
\hline Leptin $(\mathrm{Ng} / \mathrm{ml})$ & $21.32 \pm 3.68$ & $15.46 \pm 3.22^{*}$ & 5.16 & $\mathrm{P}<0.05$ \\
\hline Adiponectin $(\mu \mathrm{g} / \mathrm{mL})$ & $4.51 \pm 1.93$ & $6.12 \pm 2.14^{*}$ & 6.21 & $\mathrm{P}<0.05$ \\
\hline Resistin $(\mathrm{ng} / \mathrm{mL})$ & $15.14 \pm 3.78$ & $11.87 \pm 3.29^{*}$ & 6.27 & $\mathrm{P}<0.05$ \\
\hline Insulin $(\mathrm{mU} / \mathrm{l})$ & $16.17 \pm 3.95$ & $11.24 \pm 3.26^{*}$ & 4.97 & $\mathrm{P}<0.05$ \\
\hline QUICKI & $0.123 \pm 0.018$ & $0.159 \pm 0.027^{*}$ & 4.88 & $\mathrm{P}<0.05$ \\
\hline HOMA-IR & $5.16 \pm 1.73$ & $3.42 \pm 1.11^{*}$ & & \\
\hline
\end{tabular}




\section{Advanced Research in Gastroenterology \& Hepatology}

Table 3: Mean value and significance of leptin, adiponectin, resistin, insulin, QUICKI, HOMA-IR and BMI of group (B) before and after treatment.

\begin{tabular}{|c|c|c|c|c|}
\hline & \multicolumn{2}{|c|}{ Mean +SD } & \multirow{2}{*}{ T-value } & \multirow{2}{*}{ Significance } \\
\cline { 2 - 5 } & Before & After & 1.85 & P $>0.05$ \\
\hline BMI $\left(\mathrm{kg} / \mathrm{m}^{2}\right)$ & $32.46 \pm 3.15$ & $33.12 \pm 3.27$ & 1.46 & $\mathrm{P}>0.05$ \\
\hline Leptin $(\mathrm{Ng} / \mathrm{ml})$ & $20.75 \pm 3.13$ & $22.11 \pm 3.29$ & 1.14 & $\mathrm{P}>0.05$ \\
\hline Adiponectin $(\mu \mathrm{g} / \mathrm{mL})$ & $5.63 \pm 2.15$ & $5.58 \pm 2.32$ & 1.26 & $\mathrm{P}>0.05$ \\
\hline Resistin $(\mathrm{ng} / \mathrm{mL})$ & $16.14 \pm 3.25$ & $17.23 \pm 3.18$ & 1.39 & $\mathrm{P}>0.05$ \\
\hline Insulin $(\mathrm{mU} / \mathrm{l})$ & $15.52 \pm 3.17$ & $16.13 \pm 3.26$ & 0.75 & $\mathrm{P}>0.05$ \\
\hline QUICKI & $0.141 \pm 0.021$ & $0.121 \pm 0.018$ & 1.12 & $\mathrm{P}>0.05$ \\
\hline HOMA-IR & $5.84 \pm 2.13$ & $6.16 \pm 2.24$ & & \\
\hline
\end{tabular}

Table 4: Mean value and significance of leptin, adiponectin, resistin, insulin, QUICKI, HOMA-IR and BMI of group (A) and group (B) after treatment.

\begin{tabular}{|c|c|c|c|c|}
\hline & \multicolumn{2}{|c|}{ Mean +SD } & \multirow{2}{*}{ T-value } & \multirow{2}{*}{ Significance } \\
\cline { 2 - 4 } & Group (A) & Group (B) & 5.21 & P $<0.05$ \\
\hline BMI $(\mathrm{kg} / \mathrm{m} 2)$ & $29.63 \pm 2.45^{*}$ & $33.12 \pm 3.27$ & 5.37 & $\mathrm{P}<0.05$ \\
\hline Leptin $(\mathrm{Ng} / \mathrm{ml})$ & $15.46 \pm 3.22^{*}$ & $22.11 \pm 3.29$ & 4.15 & $\mathrm{P}<0.05$ \\
\hline Adiponectin $(\mu \mathrm{gg} / \mathrm{mL})$ & $6.12 \pm 2.14^{*}$ & $5.58 \pm 2.32$ & 5.13 & $\mathrm{P}<0.05$ \\
\hline Resistin $(\mathrm{ng} / \mathrm{mL})$ & $11.87 \pm 3.29^{*}$ & $17.23 \pm 3.18$ & 5.19 & $\mathrm{P}<0.05$ \\
\hline Insulin $(\mathrm{mU} / \mathrm{l})$ & $11.24 \pm 3.26^{*}$ & $16.13 \pm 3.26$ & 3.20 & $\mathrm{P}<0.05$ \\
\hline QUICKI & $0.159 \pm 0.027^{*}$ & $0.121 \pm 0.018$ & 3.38 & $\mathrm{P}<0.05$ \\
\hline HOMA-IR & $3.42 \pm 1.11^{*}$ & $6.16 \pm 2.24$ & & \\
\hline
\end{tabular}

BMI: Body mass index; HOMA-IR: Homeostasis Model Assessment-Insulin Resistance (HOMA-IR) index; QUICKI: The quantitative insulin-sensitivity check index; $\left({ }^{*}\right)$ indicates a significant difference between the two groups, $\mathrm{P}<0.05$.

BMI: Body mass index; HOMA-IR: Homeostasis Model Assessment-Insulin Resistance (HOMA-IR) index; QUICKI: The quantitative insulin-sensitivity check index.

BMI: Body mass index; HOMA-IR: Homeostasis Model Assessment-Insulin Resistance (HOMA-IR) index; QUICKI: The quantitative insulin-sensitivity check index; $\left({ }^{*}\right)$ indicates a significant difference between the two groups, $\mathrm{P}<0.05$.

\section{Discussion}

Non-alcoholic fatty liver disease (NAFLD) is an obesityassociated disease [32]. The prevalence of obesity and insulin resistance (IR) is increasing worldwide: over 78 million Americans are obese, and one-third have high IR [33]. It is now recognized that insulin resistance in obesity is largely consequential to adipose tissue inflammation and adipokine dysregulation [34]. To date, weight loss is the only confirmed therapy for the treatment of NAFLD, and lifestyle interventions remain the cornerstone of management $[35,36]$. The results of this study proved that weight reduction significantly modulate the insulin resistance and adipokines dysregulation among patients with NAFLD, these results are in line with many previous studies.

Regarding glucose control, this study proved that life style modification (aerobic exercise and diet regimen) significantly improved insulin resistance because of weight reduction. These results agreed with Ryan et al. [37] demonstrated in an insulin-resistant population with NAFLD a reduction of liver steatosis and an improvement of insulin sensitivity after 6 week of the Mediterranean diet, compared to current dietary advice. Moreover, Kontogianni et al. [38] reported that higher adherence to the Mediterranean diet was not associated with a less likelihood of having NAFLD, but it was associated with a lower degree of insulin resistance and less severe liver disease among patients with NAFLD. Moreover, Angelico et al. [39] proved that $5 \%-10 \%$ weight loss as a result of diet regimen modulates insulin resistance in patients with metabolic syndrome. In the other hand, Hallsworth et al. [40] showed that 8 weeks of resistance exercise in sedentary adults with NAFLD resulted in a an improvement in insulin resistance, also Bacchi et al. [41] conducted a randomized controlled trial of 31 sedentary adults with type 2 diabetes and NAFLD comparing the effects of 4 months of aerobic and resistance training on insulin sensitivity and hepatic steatosis. Hepatic fat content, hepatic steatosis and insulin sensitivity were reduced in both intervention groups. Several mechanisms have been proposed to be responsible for the increases in insulin sensitivity after exercise training. These include increased post-receptor insulin signaling, increased glucose transporter protein and mRNA, increased activity of glycogen syntheses and hexokinase, decreased release and increased clearance of free fatty acids, increased muscle glucose delivery and changes in muscle composition [42].

Concerning the levels of adipokines, this study proved that weight loss because of 12 weeks of life style modification 
(aerobic exercise and diet regimen) significantly increased the level of adiponectin and reduced the levels of both leptin and resistin. These results agreed with Copaci et al. [43] reported that 86overweight persons who achieved significant reductions in body weight through 12 months of physical activity and low caloric diet recognized significant modifications in insulin resistance, leptin and adiponectin. Oh et al. [44] stated that 12 -week exercise training program remarkably increased the serum adiponectin level and equivalent improvement of insulin resistance. mentioned that data obtained from 72 obese, middleaged men with NAFLD who completed a 3-month program of exercise and diet regimen that induced weight loss resulted in increased level of adiponectin and decreased level of leptin in addition to modulation of insulin resistance [45]. The combination of diet and exercise for three months decreased circulating leptin and BMI more than diet alone [46]. In another prospective study, the combination of aerobic and resistance exercise for 12 weeks decreased leptin levels in NAFLD patients more than aerobic exercise alone, although BMI was similarly affected [47]. In a cross-sectional study, fewer NAFLD patients were engaged in resistance training compared to controls, whereas the rates of those engaged in aerobic exercise were similar [48].

Jung et al. [49] proved that long-term exercise program and a diet led obese individuals to reduce significantly the level of resistin and leptin. Jones et al. [50] have studied the effect of 8-week aerobic exercise on lipid levels of serum, leptin, adiponectine, resistin, peptide YY, and ghreline in overweight adolescents and reported a significant decrease of resistin. Kadoglou et al. [51] studied the effect of 16-week regular aerobic exercises with a VO2max of 50 to 85 percent on resistin levels in patients with type 2 diabetic and overweight ones. They reported a significant decrease of this hormone among the participants. In the study by Elloumi et al. [52] two months of exercise with the weight loss, led to a significant decrease in resistin level among obese adolescents. Balducci et al. [53] reported that 12 months of regular physical activity could decrease the level of resistin in patients with diabetes and obesity. Rashidlamir et al. [54] stated that aerobic training for 8 weeks, 4 sessions in a week, and with the intensity of $70-80 \%$ of maximum heart rate resulted in significant reduction in BMI, fat percentage and serum resistin levels in young females.

\section{Conclusion}

Based on our findings, a $10 \%$ reduction in BMI is effective to improve glucose control and adipokines dysregulation in patients with non-alcoholic fatty liver.

\section{Acknowledgment}

This project was funded by the Deanship of Scientific Research (DSR) at King Abdulaziz University, Jeddah, under grant no. (G-42-290-37). The authors, therefore, acknowledge with thanks DSR for technical and financial support.

\section{References}

1. Mavrogiannaki AN, Migdalis IN (2013) Non-alcoholic Fatty liver disease, diabetes mellitus and cardiovascular disease: newer data. Int J Endocrinol 2013: 450639.

2. Milić S, Stimac D (2012) Non-alcoholic fatty liver disease/ steatohepatitis: epidemiology, pathogenesis, clinical presentation and treatment. Dig Dis 30(2): 158-162.

3. Petta S, Muratore C, Craxì A (2009) Non-alcoholic fatty liver disease pathogenesis: the present and the future. Dig Liver Dis 41(9): 615-625.

4. Sanyal AJ, Brunt EM, Kleiner DE, Kowdley KV, Chalasani N, et al. (2011) End points and clinical trial design for nonalcoholic steatohepatitis. Hepatology 54(1): 344-353.

5. Ekstedt M, Franzén LE, Mathiesen UL, Thorelius L, Holmqvist M, et al. (2006) Long-term follow up of patients with NAFLD and elevated liver enzymes. Hepatology 44(4): 865-873.

6. White DL, Kanwal F, El Serag HB (2012) Association between nonalcoholic fatty liver disease and risk for hepatocellular cancer, based on systematic review. Clin Gastroenterol Hepatol 10(12): 13421359.

7. Polyzos SA, Kountouras J, Zavos C (2009) Non-alcoholic fatty liver disease: the pathogenetic roles of insulin resistance and adipocytokines. Curr Mol Med 9(3): 299-314.

8. Jacobs M, van Greevenbroek MM, van der Kallen CJ, Ferreira I, Feskens EJ, et al. (2011) The association between the metabolic syndrome and alanine amino transferase is mediated by insulin resistance via related metabolic intermediates (the Cohort on Diabetes and Atherosclerosis Maastricht [CODAM] study). Metabolism 60(7): 969-75.

9. Vernon G, Baranova A, Younossi ZM (2011) Systematic review: the epidemiology and natural history of non-alcoholic fatty liver disease and non-alcoholic steatohepatitis in adults. Aliment Pharmacol Ther 34(3): 274-285.

10. Polyzos SA, Kountouras J, Zavos C, Deretzi G (2012) Non-alcoholic fatty liver disease: multimodal treatment options for a pathogenetically multiple-hit disease. J Clin Gastroenterol 46(4): 272-284.

11. Anstee QM, Targher G, Day CP (2013) Progression of NAFLD to diabetes mellitus, cardiovascular disease or cirrhosis. Nat Rev Gastroenterol Hepatol 10(6): 330-344.

12. Lonardo A, Sookoian S, Chonchol M, Loria P, Targher G (2013) Cardiovascular and systemic risk in nonalcoholic fatty liver disease atherosclerosis as a major player in the natural course of NAFLD. Curr Pharm Des 19(29): 5177-5192.

13. Vanni E, Bugianesi E, Kotronen A, De Minicis S, Yki Järvinen H, et al. (2010) From the metabolic syndrome to NAFLD or vice versa? Dig Liver Dis 42(5): 320-330.

14. El Koofy NM, Anwar GM, El Raziky MS, El Hennawy AM, El Mougy FM, et al. (2012) The association of metabolic syndrome, insulin resistance and non-alcoholic fatty liver disease in overweight/obese children. Saudi J Gastroenterol 18(1): 44-49.

15. Jang S, Lee CH, Choi KM, Lee J, Choi JW, et al. (2011) Correlation of fatty liver and abdominal fat distribution using a simple fat computed tomography protocol. World J Gastroenterol 17(28): 3335-3341.

16. Kukla M, Mazur W, Bułdak RJ, Zwirska, Korczala K (2011) Potential role of leptin, adiponectin and three novel adipokines--visfatin, chemerin and vaspin--in chronic hepatitis. Mol Med 17(11-12): 1397-1410.

17. Buechler C, Wanninger J, Neumeier M Adiponectin (2011) A key adipokine in obesity related liver diseases. World J Gastroenterol 17(23): 2801-2811. 
18. Lemoine M, Ratziu V, Kim M, Maachi M, Wendum D, et al. (2009) Serum adipokine levels predictive of liver injury in nonalcoholic fatty liver disease. Liver Int 29(9): 1431-1438.

19. Dowman JK, Tomlinson JW, Newsome PN (2011) Systematic review: the diagnosis and staging of non-alcoholic fatty liver disease and nonalcoholic steatohepatitis. Aliment Pharmacol Ther 33(5): 525-540.

20. Elloumi M, Ben-Ounis O, Makni E, Van Praagh E, Tabka Z, et al. (2009) Effect of individualized weight-loss programmes on adiponectin, leptin and resistin levels in obese adolescent boys. Acta Pædiatrica 98(9): 1487-1493.

21. Kopff B, Jegier A (2005) Adipokines: adiponectin, leptin, resistin and coronary heart disease risk. Przegl Lek; 62(3): 69-72.

22. Monsour HP, Frenette CT, Wyne K (2012) Fatty liver: a link to cardiovascular disease--its natural history, pathogenesis and treatment. Methodist Debakey Cardiovasc J 8(3): 21-25.

23. Buechler C, Wanninger J, Neumeier M (2011) Adiponectin, a key adipokine in obesity related liver diseases. World J Gastroenterol 17(23): 2801-2811.

24. Huang XD, Fan Y, Zhang H, Wang P, Yuan JP, et al. (2008) Serum leptin and soluble leptin receptor in non-alcoholic fatty liver disease. World J Gastroenterol 14(8): 2888-2893.

25. Thoma C, Day CP, Trenell MI (2012) Life style interventions for the treatment of non-alcoholic fatty liver disease in adults: a systematic review. J Hepatol 56(1): 255-266.

26. Zelber-Sagi S, Ratziu V, Oren R (2011) Nutrition and physical activity in NAFLD: an overview of the epidemiological evidence. World J Gastroenterol 17(29): 3377-3389.

27. Lazo M, Solga SF, Horska A, Bonekamp S, Diehl AM, et al. (2010) Effect of a 12-month intensive lifestyle intervention on hepatic steatosis in adults with type 2 diabetes. Diabetes Care 33(10): 2156-2163.

28. Kantartzis K, Thamer C, Peter A, Machann J, Schick F, et al. (2009) High cardiorespiratory fitness is an independent predictor of the reduction in liver fat during a lifestyle intervention in non-alcoholic fatty liver disease. Gut 58(9): 1281-1288.

29. Promrat K, Kleiner DE, Niemeier HM, Jackvony E, Kearns M, et al. (2010) Randomized controlled trial testing the effects of weight loss on nonalcoholic steatohepatitis. Hepatology 51(1): 121-129.

30. Matthews DR, Hosker JP, Rudenski AS, Naylor BA, Treacher DF, et al. (1985) Homeostasis model assessment: insulin resistance and beta cell function from plasma FBS and insulin concentrations in man. Diabetologia 28(7): 412-419.

31. Katz A, Nambi SS, Mather K, Baron DA, Follman DA, et al. (2000) Quantitative insulin sensitivity check index: a simple, accurate method for assessing insulin sensitivity in humans. J Clin Endocrinol Metab 85(7): 2402-2410.

32. Wolfs MG, Gruben N, Rensen SS, Verdam FJ, Greve JW, et al. (2015) Determining the association between adipokine expression in multiple tissues and phenotypic features of non-alcoholic fatty liver disease in obesity. Nutr Diabetes 5: e146.

33. Yanovski SZ, Yanovski JA (2011) Obesity prevalence in the United States -up, down, or sideways? New England Journal of Medicine 364: 987-989.

34. Tilg H, Moschen AR (2010) Evolution of inflammation in nonalcoholic fatty liver disease: the multiple parallel hits hypothesis. Hepatology 52(5): 1836-1846.

35. Day CP (2006) Non-alcoholic fatty liver disease: current concepts and management strategies. Clin Med 6(1): 19-25.
36. Harrison S, Day C (2006) Benefits of lifestyle modification in NAFLD. Gut 56(12): 1760-1769.

37. Ryan MC, Itsiopoulos C, Thodis T, Ward G, Trost N, et al. (2013) The Mediterranean diet improves hepatic steatosis and insulin sensitivity in individuals with non-alcoholic fatty liver disease. J Hepatol 59(1): 138-143.

38. Kontogianni MD, Tileli N, Margariti A, Georgoulis M, Deutsch M, et al. (2014) Adherence to the Mediterranean diet is associated with the severity of non-alcoholic fatty liver disease. Clin Nutr 33(4): 678-683.

39. Angelico F, Loffredo L, Pignatelli P, Augelletti T, Carnevale R, et al. (2012) Weight loss is associated with improved endothelial dysfunction via NOX2-generated oxidative stress downregulation in patients with the metabolic syndrome. Intern Emerg Med 7(3): 219-227.

40. Hallsworth K, Fattakhova G, Hollingsworth KG, Thoma C, Moore S, et al. (2011) Resistance exercise reduces liver fat and its mediators in non-alcoholic fatty liver disease independent of weight loss. Gut 60(9): 1278-1283.

41. Bacchi E, Negri C, Targher G, Faccioli N, Lanza M, et al. (2013) Both resistance training and aerobic training reduce hepatic fat content in type 2 diabetic subjects with nonalcoholic fatty liver disease (the RAED2 randomized trial). Hepatology 58(4): 1287-1295.

42. Ahmadizad S, Haghighi A, Hamedinia M (2007) Effects of resistance versus endurance training on serum adiponectin and insulin resistance index European Journal of Endocrinology 157(5): 625-631.

43. Copaci I, Lupescu I, Caceaune E, Chiriac G, Ismail G (2015) Non invasive Markers of Improvement of Liver Steatosis Achieved by Weight Reduction in Patients with Nonalcoholic Fatty Liver Disease. Rom J Intern Med 53(1): 54-62.

44. Oh S, Tanaka K, Warabi E, Shoda J (2013) Exercise reduces inflammation and oxidative stress in obesity-related liver diseases. Med Sci Sports Exerc 45(12): 2214-2222.

45. Oh S, Tanaka K, Tsujimoto T, So R, Shida T, et al. (2014) Regular exercise coupled to diet regimen accelerates reduction of hepatic steatosis and associated pathological conditions in nonalcoholic fatty liver disease. Metab Syndr Relat Disord 12(5): 290-298.

46. Oh S, Tanaka K, Tsujimoto T, So R, Shida T, et al. (2014) Regular exercise coupled to diet regimen accelerates reduction of hepatic steatosis and associated pathological conditions in nonalcoholic fatty liver disease. Metab Syndr Relat Disord 12(5): 290-298.

47. De Piano A, De Mello MT, Sanches Pde L, Da Silva PL, Campos RM, et al. (2012) Long-term effects of aerobic plus resistance training on the adipokines and neuropeptides in nonalcoholic fatty liver disease obese adolescents. Eur J Gastroenterol Hepatol 24(11): 1313-1324.

48. Zelber-Sagi S, Nitzan-Kaluski D, Goldsmith R, Webb M, Zvibel I, et al. (2008) Role of leisure-time physical activity in nonalcoholic fatty liver disease: a population-based study. Hepatology 48(6): 1791-1798.

49. Jung SH, Park HS, Kim KS, Choi WH, Ahn CW, et al. (2008) Effect of weight loss on some serum cytokines in human obesity:increase in IL10 after weight loss. J Nutr Biochem 19(6): 371-375.

50. Jones TE, Basilio JL, Brophy PM, McCammon MR, Hicknern RC (2009) Long-term Exercise Training in Overweight Adolescents Improves Plasma Peptide YY and Resistin. Obesity 17(6): 1189-1195.

51. Kadoglou NP, Perrea D, Iliadis F, Angelopoulou N, Liapis C, et al. (2007) Exercise Reduces Resistin and Inflammatory Cytokines in Patients With Type 2 Diabetes. Diabetes Care 30(3): 719-721.

52. Elloumi M, Ben Ounis O, Makni E, Van Praagh E, Tabka Z, et al. (2009) Effect of individualized weight-loss programmes on adiponectin, leptin and resistin levels in obese adolescent boys. Acta Pædiatrica 98(9): 1487-1493. 
53. Balducci S, Zanuso S, Nicolucci A, Fernando F, Cavallo S, et al. (2010) Anti-inflammatory effect of exercise training in subjects with type 2 diabetes and the metabolic syndrome is dependent on exercise modalities and independent of weight loss. Nutr Metab Cardiovasc Dis 20(8): 608-617.
54. Rashidlamir A, Gholamian S, Atri A (2013) Regular Aerobic Exercise Decreases Serum Resistin levels In Active Young Females. International Journal of Sport Studies 3(6): 630-636.

Your next submission with JuniperPublishers will reach you the below assets

- Quality Editorial service

- Swift Peer Review

- Reprints availability

- E-prints Service

- Manuscript Podcast for convenient understanding

- Global attainment for your research

- Manuscript accessibility in different formats ( Pdf, E-pub, Full Text, audio)

- Unceasing customer service

Track the below URL for one-step submission https://juniperpublishers.com/online-submission.php 